\title{
Clinical spectrum and short-term outcomes of multisystem inflammatory syndrome in children in a south Indian hospital
}

Muruganantham Balagurunathan, MD*, Thrilok Natarajan, MD, MRCPCH (UK)*, Jothilakshmi Karthikeyan, DNB, Venkateshwaran Palanisamy, MD

Department of Pediatrics, PSG Institute of Medical Sciences and Research, Tamilnadu, India

Background: Multisystem inflammatory syndrome in children (MIS-C) is a new hyperinflammatory variant that evolved during the coronavirus disease 2019 pandemic. Although the precise pathophysiology of MIS-C is uncertain, it is thought to be due to immune dysregulation occurring after recovery from acute infection.

Purpose: Our study aimed to analyze the clinical spectrum, laboratory parameters, imaging characteristics, treatment strategies, and short-term outcomes of children with a diagnosis of MIS-C.

Methods: This retrospective and prospective observational study included children less than 16 years of age who were admitted to the pediatric unit of a tertiary care teaching hospital in south India between August 2020 to January 2021 with a diagnosis of MIS-C according to World Health Organization criteria.

Results: Twenty-one children were included in the analysis; all had fever with variable combinations of other symptoms. The mean age was 6.9 years; $71.4 \%$ were male. Gastrointestinal $(80.9 \%)$ and cardiovascular (80.9\%) systems were the most commonly affected. The majority of children had elevated inflammatory markers, and 16 (76.2\%) had echocardiographic abnormalities mimicking Kawasaki disease. Eleven children $(52.4 \%)$ required intensive care admission, $3(14.3 \%)$ required supplemental oxygen, and 4 (19\%) required inotropes. Nine $(42.9 \%)$ were treated with intravenous immunoglobulin alone, $6(28.6 \%)$ with steroids alone, and $3(14.3 \%)$ with steroids and immunoglobulin. The median hospital stay was 6 days; there were no fatalities. Overweight/obesity, elevated ferritin, and mucocutaneous involvement were significantly associated with a prolonged hospital stay ( $\geq 7$ days). Sixteen children (76.2\%) were followed up till now and all of them had no clinical concerns.

Conclusion: MIS-C is an emerging disease with variable presentation. A high index of suspicion is necessary for its early identification and appropriate management. Further research is essential for developing optimal treatment strategies.
Key words: Clinical spectrum, Coronavirus disease 2019, Kawasaki disease, Multisystem inflammatory syndrome in children

\section{Key message}

- Question: What are the clinical spectrum, course, and shortterm outcomes of multisystem inflammatory syndrome in children (MIS-C)?

- Finding: MIS-C can have variable clinical manifestations. Fever is most common, followed by gastrointestinal and cardiovascular symptoms. Early identification and appropriate management lead to favorable outcomes.

- Meaning: MIS-C can present in a myriad of ways and severities. High suspicion is necessary to ensure its early identification and appropriate management and favorable patient outcomes.

\section{Introduction}

The coronavirus disease 2019 (COVID-19) pandemic in India is a part of the global pandemic caused by severe acute respiratory syndrome corona virus-2 (SARS-CoV-2). India is one of the countries with the highest burden of confirmed COVID-19 cases in the world and ranks second in the list of countries with a maximum number of cases. ${ }^{1)}$ Earlier reports suggested that children infected with COVID-19 were highly resilient and could present with only a mild upper respiratory illness. ${ }^{2-4)}$ But in April 2020, clinicians in the United Kingdom reported a cluster of previously healthy children presenting with shock, fever, and hyper inflammation. ${ }^{5)}$ The Royal College of Paediatrics and Child Health referred to this acute condition as pediatric inflammatory multisystem syndrome temporally associated with SARS-CoV-2. ${ }^{6}$ As the pandemic progressed and the number of such cases increased globally the illness was labelled as multisystem inflammatory syndrome in children (MIS-C) by the Centers for Disease Control and Prevention and

\footnotetext{
Corresponding author: Thrilok Natarajan, MD, MRCPCH (UK), 9/8-D, Sathy road, S.S.Kulam, Coimbatore-641107, Tamilnadu, India 凶Email: dr.thrilz@gmail.com, https://orcid.org/0000-0003-1589-9162

*These authors contributed equally to this study as co-first authors.

Received: 30 March, 2021, Revised: 26 June, 2021, Accepted: 15 July, 2021

This is an open-access article distributed under the terms of the Creative Commons Attribution Non-Commercial License (http://creativecommons.org/licenses/by-nc/4.0/) which permits unrestricted non-commercial use, distribution, and reproduction in any medium, provided the original work is properly cited. Copyright (c) 2021 by The Korean Pediatric Society
} 
Clinical spectrum of multisystem inflammatory syndrome in children

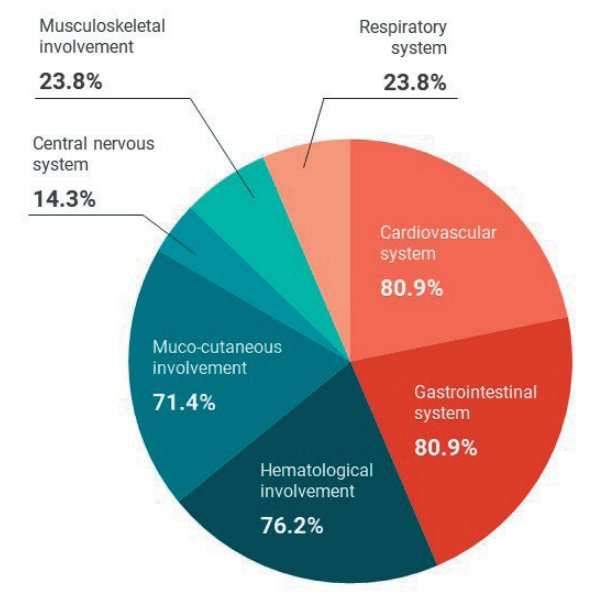

- Intensive care admission - $\mathbf{5 2 . 4 \%}$

- Supplemental oxygen requirement - $14.3 \%$

- Inotrope requirement - $19 \%$

- Abnormal echocardiogram - 76.2\%

- Mortality - $0 \%$

- Follow-up $-76.2 \%$

Graphical abstract

the World Health Organization (WHO), ${ }^{78}$ Although the exact pathophysiology of MIS-C is uncertain, it is thought to be due to immune dysregulation occurring after recovery from acute infection. As the burden of COVID-19 infection is increasing in India, more children are being recognized with this condition. Although many articles are reported from western countries there is a dearth of published reports from Asian countries.

Our study aimed at analyzing the clinical spectrum, laboratory parameters, and imaging characteristics of children less than 16 years admitted with a diagnosis of MIS-C. In addition, this study aimed to analyze the treatment strategies and short-term outcomes.

\section{Methods}

\section{Study design and setting}

This study was a partly retrospective and partly prospective observational study done in children admitted with a diagnosis of MIS-C in a tertiary care teaching hospital in south India from August 2020 to January 2021. The hospital is one of the largest COVID-19 care centers in south India and receives referrals from a radius of 200 kilometers. The study was approved by the Institutional Human Ethics Committee of PSGIMS\&R (project No. 20/262 dated 27th November, 2020). Informed written consent was obtained from parents prior to the inclusion of children in the prospective part of the study. Waiver of consent was obtained for the retrospective collection of data.

\section{Participants}

Children less than 16 years of age diagnosed with MIS-C as per WHO criteria were included in the study. The following parameters were considered for diagnosis: (1) fever $\geq 3$ days, (2) 2 of the following: a) rash or bilateral nonpurulent conjunctivitis or mucocutaneous inflammation signs (oral mucosa, hands, or feet), b) hypotension or shock, c) features of myocardial dysfunction, pericarditis, valvulitis, or coronary abnormalities (including echocardiography findings or elevated troponin/N-terminal pro-B-type natriuretic peptide [NTproBNP]), d) evidence of coagulopathy (by prothrombin time, partial thromboplastin time, elevated D-dimers), e) Acute gastrointestinal problems [diarrhea, vomiting, or abdominal pain], (3) elevated markers of inflammation such as erythrocyte sedimentation rate, C-reactive protein, or procalcitonin, (4) no other obvious microbial cause of inflammation, including bacterial sepsis, staphylococcal or streptococcal toxic shock syndromes, (5) evidence of COVID-19 (real-time reverse transcription polymerase chain reaction [RT-PCR], antigen test or serology positive), or likely contact with patients with COVID-19.

\section{Data collection}

Data on demographics, clinical features, laboratory results, imaging studies, treatment details, outcomes, and followup were collected. All the investigations and treatment were carried out as per institutional protocol and treating physician's discretion.

COVID-19 infection was confirmed by testing for SARSCoV-2 antibody by chemiluminescence immunoassay (VITROS 3600 immunodiagnostic system, Ortho Clinical Diagnostics, Raritan, NJ, USA) and/or RT-PCR as recommended by Indian Council of Medical Research. The laboratory values were interpreted as either increased or decreased based on the agespecific normal reference ranges. Organ system involvement was described based on clinical features, laboratory reports, and imaging studies. Echocardiography was performed in all children by the pediatric cardiologist to identify the following abnormalities; (a) left ventricular dysfunction (ejection fraction 
less than 55\%), (b) pericarditis or pericardial effusion, (c) coronary artery abnormalities (dilatation, aneurysm, or irregular nontapering coronary arteries), or (d) valvular regurgitation. The dimension of the coronary artery was measured as per standard criteria and a coronary z score above 2 was reported as dilated. Other imaging studies were done as clinically indicated.

\section{Statistical analysis}

Data analysis was done using Microsoft Excel 2019 (Microsoft Corp., Redmond, WA, USA). Descriptive statistics were used to summarize population characteristics. Categorical variables were expressed as frequency or percentage and continuous variables were expressed as mean with standard deviation or median with interquartile range. IBM SPSS Statistics ver. 26.0 (IBM Co., Armonk, NY, USA) was used to perform univariate analysis and a $P$ value of $<0.05$ was considered significant.

\section{Results}

From August 2020 to January 2021, 21 children met the WHO MIS-C criteria and were included in the analysis. Among them, only 2 children were admitted with active coronavirus- 2 infection and were subsequently diagnosed as MIS-C. The demographic and clinical characteristics of the study population are mentioned in Table 1 . The mean age of the study population was 6.9 years and $71.4 \%$ were male. All children were previously healthy and 9.5\% were either obese or overweight.

All patients had fever with a variable combination of other symptoms. Gastrointestinal symptoms like abdominal pain, diarrhea, and vomiting were the most common presenting symptoms. The mean duration of symptoms prior to admission was 4.8 days and the mean total duration of fever was 7.9 days. The majority of children in this series had multiorgan involvement. Gastrointestinal (80.9\%) and cardiovascular (80.9 $\%)$ systems were the most commonly affected organ systems. This was followed by hematological (76.2\%), mucocutaneous (71.4\%), and central nervous system (14.2\%) involvement. None of the children had acute kidney injury in this series. Two children in this series had been treated for COVID-19 3 weeks prior to the diagnosis of MIS-C, and 5 children had history of confirmed exposure to COVID-19 patients in the preceding 3 to 4 weeks. In other children, no history associated with COVID-19 was revealed.

In the study population, 19 children (90.4\%) had positive COVID-19 antibody tests, 1 (4.8\%) had positive COVID-19 RT-PCR test, and another (4.8\%) had both positive COVID-19 RT-PCR and antibody tests. The results of laboratory tests and imaging studies are summarized in Tables 2 and 3. Lymphopenia and thrombocytopenia were seen in $47.6 \%$ and $38.1 \%$ of cases, respectively. Inflammatory markers were elevated in the majority of cases. Specifically, D-dimer and interleukin 6 (IL-6) were elevated in 95.2\% and 90.5\% of cases, respectively. Children with cardiovascular system involvement showed elevation of
Table 1. Patients' demographic and clinical characteristics

\begin{tabular}{|c|c|}
\hline Population characteristics & Value \\
\hline Age (yr) & $6.9 \pm 4$ \\
\hline Male sex & $15(71.4)$ \\
\hline Weight (kg), median (IQR) & $20(12.8-35.5)$ \\
\hline Overweight/obesity & $2(9.5)$ \\
\hline Duration of symptoms at admission (day) & $4.8 \pm 2.1$ \\
\hline Contact with COVID-19 patient & $5(23.8)$ \\
\hline Past COVID-19 infection & $2(9.5)$ \\
\hline \multicolumn{2}{|l|}{ Clinical features } \\
\hline \multicolumn{2}{|l|}{ General } \\
\hline Fever & $21(100)$ \\
\hline Total duration of fever (day) & $7.9 \pm 3.1$ \\
\hline Highest temperature recorded in hospital admission $\left({ }^{\circ} \mathrm{F}\right)$ & $102.4 \pm 1.8$ \\
\hline Giddiness & $1(4.8)$ \\
\hline Fatigue \pm lethargy & $13(61.9)$ \\
\hline Headache & $5(23.8)$ \\
\hline \multicolumn{2}{|l|}{ Respiratory } \\
\hline Cough & $2(9.5)$ \\
\hline Sore throat/ throat pain & $3(14.3)$ \\
\hline Runny nose \pm sneezing & $1(4.8)$ \\
\hline Fast breathing & $4(19)$ \\
\hline \multicolumn{2}{|l|}{ Gastrointestinal } \\
\hline Nausea & $3(14.3)$ \\
\hline Vomiting & $12(57.1)$ \\
\hline Diarrhea & $11(52.4)$ \\
\hline Abdominal pain & $11(52.4)$ \\
\hline Abdominal distension & $5(23.8)$ \\
\hline \multicolumn{2}{|l|}{ Musculoskeletal } \\
\hline Joint pain & $1(4.8)$ \\
\hline Myalgia & $7(33.3)$ \\
\hline \multicolumn{2}{|l|}{ Mucocutaneous } \\
\hline Rash & $8(38.1)$ \\
\hline Bilateral nonexudative conjunctivitis & $12(57.1)$ \\
\hline Lymphadenopathy & $3(14.3)$ \\
\hline Strawberry tongue \pm cracked lips & $7(33.3)$ \\
\hline Oedema/erythema of hands and feet & $6(28.6)$ \\
\hline \multicolumn{2}{|l|}{ Cardiovascular } \\
\hline Shock requiring inotropes & $4(19)$ \\
\hline \multicolumn{2}{|l|}{ Neurological } \\
\hline Seizures & $1(4.8)$ \\
\hline Altered level of consciousness & $3(14.3)$ \\
\hline Cerebellar signs & $1(4.8)$ \\
\hline Focal neurological deficit & $1(4.8)$ \\
\hline \multicolumn{2}{|l|}{ Organ system involvement ${ }^{a)}$} \\
\hline One & $1(4.8)$ \\
\hline Two & $3(14.3)$ \\
\hline Three & $4(19)$ \\
\hline Four or more & $13(61.9)$ \\
\hline
\end{tabular}

Values are presented as mean \pm standard deviation or number (\%) unless otherwise indicated.

IQR, interquartile range; COVID-19, coronavirus disease 2019.

a) Organ system involvement was classified as cardiovascular, gastrointestinal, respiratory, nervous, musculoskeletal, hematological, or renal based on clinical features and investigations. 
Table 2. Laboratory test results

\begin{tabular}{|c|c|c|}
\hline Parameter & Number (\%) & Definition \\
\hline \multicolumn{3}{|l|}{ Blood counts } \\
\hline Anemia & 4/21 (19) & $\begin{array}{l}\mathrm{Hb}<10 \mathrm{~g} / \mathrm{dL} \text { in }<1 \mathrm{yr} \\
\mathrm{Hb}<9 \mathrm{~g} / \mathrm{dL} \text { in } \geq 1 \mathrm{yr}\end{array}$ \\
\hline Neutrophilia & $16 / 21(76.2)$ & ANC $>7.7 \times 10^{3}$ cells $/ \mu \mathrm{L}$ \\
\hline Lymphopenia & $10 / 21(47.6)$ & $\begin{array}{l}\text { ALC }<1.5 \times 10^{3} \text { cells } / \mu \mathrm{L} \text { in child } \\
>8 \mathrm{mo} \\
\text { ALC }<4.5 \times 10^{3} \text { cells } / \mu \mathrm{L} \text { in child } \\
<8 \mathrm{mo}\end{array}$ \\
\hline Thrombocytopenia & $8 / 21(38.1)$ & Platelet $<150 \times 10^{3}$ cells $/ \mathrm{mm}^{3}$ \\
\hline Thrombocytosis & 6/21 (28.6) & Platelet $>500 \times 10^{3}$ cells $/ \mathrm{mm}^{3}$ \\
\hline \multicolumn{3}{|l|}{ Inflammatory markers } \\
\hline Elevated ESR & $17 / 20(85)$ & $\geq 40 \mathrm{~mm} / \mathrm{hr}$ \\
\hline Elevated CRP & $20 / 20(100)$ & $\geq 0.6 \mathrm{mg} / \mathrm{dL}$ \\
\hline Elevated procalcitonin & $5 / 5(100)$ & $\geq 0.5 \mathrm{ng} / \mathrm{mL}$ \\
\hline Elevated ferritin & 9/21 (42.9) & $>500 \mathrm{ng} / \mathrm{mL}$ \\
\hline Elevated IL-6 & 19/21 (90.5) & $\geq 7 \mathrm{pg} / \mathrm{mL}$ \\
\hline Elevated LDH & $11 / 16(68.8)$ & $\mathrm{LDH}>300 \mathrm{U} / \mathrm{L}$ \\
\hline \multicolumn{3}{|l|}{ Electrolytes } \\
\hline Hyponatremia & 12/17 (70.6) & Sodium $<135 \mathrm{mEq} / \mathrm{L}$ \\
\hline Hypokalemia & $8 / 17(47.1)$ & Potassium $<3.5 \mathrm{mEq} / \mathrm{L}$ \\
\hline \multicolumn{3}{|l|}{ Liver function test } \\
\hline Elevated AST & 6/17 (35.3) & $\mathrm{AST}>40 \mathrm{U} / \mathrm{L}$ \\
\hline Elevated ALT & $5 / 17(29.4)$ & $\mathrm{ALT}>40 \mathrm{U} / \mathrm{L}$ \\
\hline Hypoalbuminemia & 9/17 (52.9) & Albumin $<3 \mathrm{~g} / \mathrm{dL}$ \\
\hline \multicolumn{3}{|l|}{ Cardiac biomarkers } \\
\hline Elevated troponin-T & 4/13 (30.8) & $\geq 14 \mathrm{pg} / \mathrm{mL}$ \\
\hline Elevated NT-proBNP & $12 / 15(80)$ & $>450 \mathrm{pg} / \mathrm{mL}$ \\
\hline \multicolumn{3}{|l|}{ Coagulation profile } \\
\hline Elevated D-dimer & 20/21 (95.2) & $\geq 0.5 \mathrm{mg} / \mathrm{L} \mathrm{FEU}$ \\
\hline Deranged coagulation & $2 / 8(25)$ & INR $\geq 1.2$ \\
\hline \multicolumn{3}{|c|}{$\begin{array}{l}\text { Hb, hemoglobin; ANC, absolute neutrophil counts; ALC, absolute lymphocyte } \\
\text { counts; ESR, erythrocyte sedimentation rate; CRP, C-reactive protein; IL } \\
\text { interleukin; LDH, lactate dehydrogenase; AST, aspartate aminotransferase } \\
\text { ALT, alanine aminotransferase; NT-proBNP, N-terminal prohormone of } \\
\text { brain natriuretic peptide; FEU, fibrinogen equivalent units; INR, internationa } \\
\text { normalized ratio. }\end{array}$} \\
\hline
\end{tabular}

cardiac biomarkers, and NT-proBNP (80\%) was found to be more commonly elevated than troponin-T (30.8\%). Electrolyte imbalances like hyponatremia and hypokalemia were seen in $70.6 \%$ and $47.1 \%$ of cases, respectively, which were managed appropriately.

Echocardiography was performed in all the children, and abnormality was noted in 16 children (76.2\%). A greater number of children had a combination of abnormalities rather than a single abnormal finding. Coronary artery abnormality (57.1\%) was the most common finding, followed by pericardial effusion (52.4\%), left ventricular dysfunction (23.8\%), and mitral regurgitation (23.8\%). Gastrointestinal imaging studies like x-ray, ultrasound, and computed tomography were done as indicated, and ascites (50\%) was the most common abnormality, followed by dilated bowel loops (35.7\%), and mesenteric lymphadenitis (35.7\%). Of the 17 patients who underwent chest imaging ( $\mathrm{x}$-ray or computed tomography), pleural effusion and lung infiltrates were observed in $3(17.6 \%)$ and 1 patient (5.9\%),
Table 3. Results of COVID-19 tests and imaging studies

\begin{tabular}{lc}
\hline Variable & Number (\%) \\
\hline COVID-19 test results & $19(90.4)$ \\
Positive serology alone & $1(4.8)$ \\
Positive RT-PCR alone & $1(4.8)$ \\
Both serology and RT-PCR positive & \\
Chest imaging ( $\mathrm{n}=17)$ & $3(17.6)$ \\
Pleural effusion & $1(5.9)$ \\
Lung infiltrates & \\
Gastrointestinal imaging (n=14) & $7(50)$ \\
Ascites & $5(35.7)$ \\
Mesenteric lymphadenitis & $5(35.7)$ \\
Dilated bowel loops & $3(21.4)$ \\
Appendicular inflammation & $1(7.1)$ \\
Appendicular abscess & $3(21.4)$ \\
Hepatomegaly & $1(7.1)$ \\
Gallbladder wall thickening & \\
Echocardiography findings ( $\mathrm{n}=21)$ & $16(76.2)$ \\
Abnormal ECHO & $12(57.1)$ \\
Coronary artery abnormality & $11(52.4)$ \\
Pericardial effusion & $5(23.8)$ \\
Left ventricular dysfunction & $5(23.8)$ \\
Mitral regurgitation & \\
\hline COVID-19, coronavirus disease 2019; RT-PCR, reverse transcription \\
polymerase chain reaction; ECHO, echocardiogram.
\end{tabular}

Table 4. Treatment details and outcomes

\begin{tabular}{lc}
\hline Variable & Value \\
\hline Highest level of care & $11(52.4)$ \\
PICU admission & $74.8 \pm 41.6$ \\
Duration of PICU stay (hr) & \\
Respiratory support & $3(14.3)$ \\
Supplemental oxygen requirement & $39.6 \pm 28.6$ \\
Duration of oxygen requirement (hr) & $1(4.8)$ \\
High flow nasal cannula & \\
Circulatory support & $4(19)$ \\
Inotropic support & $37 \pm 24.5$ \\
Duration of inotrope requirement (hr) & \\
Pharmacotherapy & $18(85.7)$ \\
Antibiotics & $9(42.9)$ \\
Intravenous immunoglobulin alone & $6(28.6)$ \\
Steroids (intravenous or oral) alone & $3(14.3)$ \\
Both intravenous immunoglobulin and steroids & $14(66.7)$ \\
Aspirin & $3(14.3)$ \\
Anticoagulant & $1(4.8)$ \\
Antiepileptics & \\
Outcomes & $6(5-8)$ \\
Length of hospital stay (day), median (IQR) & $0(0)$ \\
Mortality & $16(76.2)$ \\
\hline Follow-up & \\
\hline Val & \\
\hline
\end{tabular}

Values are presented as number (\%) or mean \pm standard unless otherwise indicated.

PICU, pediatric intensive care unit; IQR, interquartile range. 
respectively. Of the 3 children with central nervous system involvement, 1 had encephalopathy with features of cerebellar involvement, 1 had seizures, and another had headache with bilateral papilledema. All 3 children with central nervous system involvement showed normal neuroimaging. Two children underwent cerebrospinal fluid analysis, and findings of aseptic meningitis were seen in the patient who presented with encephalopathy.

Treatment details and outcomes are summarized in Table 4. Eleven children (52.4\%) required pediatric intensive care unit (PICU) admission and the mean duration of PICU stay was 74.8 hours. Three children (14.3\%) required supplemental oxygen, and none of the children required mechanical ventilation. Four children (19\%) required inotropic support for hemodynamic instability, and the mean duration of inotrope requirement was 37 hours. Nine children (42.9\%) were treated with intravenous immunoglobulin (IVIG) alone, 6 (28.6\%) were treated with steroids alone and 3 (14.3\%) were treated with both IVIG and steroids. None of the cases required other immunomodulators for treatment.

An 8-year-old girl presented with features of acute appendicitis, and an emergency surgery was done, which revealed a perforated appendix with abscess collection. She was subsequently diagnosed as MIS-C and was treated with IVIG.

The median length of hospitalization was 6 days in this series. Table 5 shows the results of univariate analysis for prolonged hospital stay ( $\geq 7$ days). Children who were either overweight or obese $(P=0.035)$, had elevated ferritin $(P=0.019)$, or had mucocutaneous involvement $(P=0.040)$ were found to be significantly associated with prolonged hospital stay. Further extensive analysis could not be performed due to small sample size. There was no mortality in patients of our study, and all patients were discharged home. At the time of writing this article, 16 patients $(76.2 \%)$ had attended follow-up visits.

Table 5. Results of univariate analysis of factors associated with prolonged hospital stay $(\mathrm{n}=\mathbf{2 1})$

\begin{tabular}{|c|c|c|c|c|}
\hline Variable & $\begin{array}{l}\text { Hospital stay }<7 \text { days } \\
(n=14), n(\%)\end{array}$ & $\begin{array}{c}\text { Hospital stay } \geq 7 \text { days } \\
(n=7), n(\%)\end{array}$ & $P$ value & OR $(95 \% \mathrm{Cl})$ \\
\hline Age groups & & & 0.376 & - \\
\hline Less than 5 yr $(n=7)$ & $6(85.7)$ & $1(14.3)$ & & \\
\hline 5 to 9 yr $(n=6)$ & $3(50.0)$ & $3(50.0)$ & & \\
\hline 10 to $15 \mathrm{yr}(\mathrm{n}=8)$ & $5(62.5)$ & $3(37.5)$ & & \\
\hline Sex & & & 1.000 & $1.000(0.134-7.451)$ \\
\hline Male $(n=15)$ & $10(66.7)$ & $5(33.3)$ & & \\
\hline Female $(n=6)$ & $4(66.7)$ & $2(33.3)$ & & \\
\hline Overweight/obesity ( $n=2$ ) & $0(0)$ & $2(100)$ & 0.035 & $0.263(0.124-0.558)$ \\
\hline Temperature $>38.9^{\circ} \mathrm{C}(\mathrm{n}=11)$ & $5(45.5)$ & $6(54.5)$ & 0.089 & $10.80(0.997-116.998)$ \\
\hline Anemia $(n=4)$ & $2(50.0)$ & $2(50.0)$ & 0.432 & $2.400(0.261-22.105)$ \\
\hline Lymphopenia $(n=10)$ & $5(50.0)$ & $5(50.0)$ & 0.122 & $4.500(0.627-32.295)$ \\
\hline Thrombocytopenia $(n=8)$ & $6(75.0)$ & $2(25.0)$ & 0.525 & $0.533(0.076-3.755)$ \\
\hline Elevated ESR $(n=17)$ & $12(70.6)$ & $5(29.4)$ & 0.212 & $0.208(0.015-2.854)$ \\
\hline Elevated ferritin $(n=9)$ & $3(33.3)$ & $6(66.7)$ & 0.019 & $22.0(1.857-260.648)$ \\
\hline Elevated IL-6 (n=19) & $12(63.2)$ & $7(33.3)$ & 0.293 & - \\
\hline Elevated D-dimer $(n=20)$ & $13(65.0)$ & $7(35.0)$ & 0.469 & - \\
\hline Hyponatremia $(n=12)$ & $6(50.0)$ & $6(50.0)$ & 0.252 & $4.000(0.340-47.112)$ \\
\hline Hypokalemia $(n=8)$ & $4(50.0)$ & $4(50.0)$ & 0.486 & $2.000(0.282-14.198)$ \\
\hline Hypoalbuminemia $(n=9)$ & $5(55.6)$ & $4(44.4)$ & 0.772 & $1.333(1.191-9.311)$ \\
\hline Abnormal ECHO (n=16) & $10(62.5)$ & $6(37.5)$ & 0.469 & $2.400(0.215-26.822)$ \\
\hline PICU admission $(n=12)$ & $7(58.3)$ & $5(41.7)$ & 0.350 & $2.500(0.357-17.500)$ \\
\hline Supplemental oxygen requirement $(n=3)$ & $1(33.3)$ & $2(66.7)$ & 0.186 & $5.200(0.381-70.903)$ \\
\hline Inotropic support $(\mathrm{n}=4)$ & $2(50.0)$ & $2(50.0)$ & 0.432 & $2.400(0.261-22.105)$ \\
\hline \multicolumn{5}{|l|}{ Organ system involvement } \\
\hline Cardiovascular system $(n=17)$ & $10(58.8)$ & $7(41.2)$ & 0.116 & - \\
\hline Respiratory system (n=5) & $2(40.0)$ & $3(60.0)$ & 0.147 & $4.500(0.542-37.378)$ \\
\hline Gastrointestinal system $(n=17)$ & $11(64.7)$ & $6(35.3)$ & 0.694 & $1.636(0.138-19.387)$ \\
\hline Central nervous system $(n=3)$ & $2(66.7)$ & $1(33.3)$ & 1.000 & $1.000(0.075-13.367)$ \\
\hline Hematological system ( $\mathrm{n=16}$ ) & $9(56.3)$ & $7(43.8)$ & 0.070 & $1.778(1.154-2.379)$ \\
\hline Mucocutaneous involvement $(n=15)$ & $12(80.0)$ & $3(20.0)$ & 0.040 & $0.125(0.15-1.038)$ \\
\hline Musculoskeletal system $(n=5)$ & $3(60.0)$ & $2(40.0)$ & 0.717 & $1.467(0.184-11.718)$ \\
\hline Multiorgan involvement ( $\geq 4$ organs) $(n=13)$ & $8(61.5)$ & $5(38.5)$ & 0.525 & $1.875(0.266-13.202)$ \\
\hline
\end{tabular}

$\mathrm{OR}$, odds ratio; $\mathrm{Cl}$, confidence interval; ESR, erythrocyte sedimentation rate; IL, interleukin; ECHO, echocardiogram; PICU, pediatric intensive care unit. Boldface indicates a statistically significant difference with $P<0.05$. 
Table 6. Common clinical characteristics in our study versus those of other studies

\begin{tabular}{lcrc}
\hline Clinical feature & Our study $(n=21)$ & Whittaker et al. ${ }^{10)}(\mathrm{n}=58)$ & Dhanalakshmi et al. ${ }^{11)}(\mathrm{n}=19)$ \\
\hline Fever & $21(100)$ & $58(100)$ & $19(100)$ \\
Vomiting & $12(57.1)$ & $26(45)$ & $6(31.5)$ \\
Abdominal pain & $11(52.4)$ & $31(53)$ & $8(42)$ \\
Diarrhea & $11(52.4)$ & $30(52)$ & $3(15.8)$ \\
Rash & $8(38.1)$ & $30(52)$ & $12(63.2)$ \\
Bilateral conjunctival congestion & $12(57.1)$ & $26(45)$ & $9(47.4)$ \\
Cervical lymphadenopathy & $3(14.3)$ & $9(16)$ & $6(31.5)$ \\
Strawberry tongue \pm cracked lips & $7(33.3)$ & $17(29)$ & $9(47.4)$ \\
Oedema/erythema of hands and feet & $6(28.6)$ & $9(16)$ & $10(52.6)$ \\
\hline
\end{tabular}

Values are presented as number (\%).

Among them, 11 children (52.4\%) had attended one followup visit, and 5 (23.8\%) had attended 2 follow-up visits, all of whom had no clinical concerns. Among 16 children with abnormal echocardiography, 12 (75\%) underwent follow-up echocardiography, and their cardiac imaging showed partial or complete resolution of previous abnormalities. Further followup echocardiography was recommended to some of them.

\section{Discussion}

MIS-C is an evolving concept of disease and its exact incidences in different geographic areas are uncertain. The focus of this study was to analyze the clinical spectrum and short-term outcomes of children with MIS-C managed in a tertiary care teaching hospital in south India. We described 21 children under the age of 16 years with MIS-C associated with SARS-CoV-2 infection. All these children had evidences of previous or active COVID-19 infection. The spectrum of clinical presentations in our study was broadly consistent with available literatures. The mean age of children in this study was 6.9 years, and 61.9\% of affected children were above 5 years, which was similar to studies by Kaushik et al., ${ }^{9}$ Whittaker et al., ${ }^{10)}$ and Dhanalakshmi et al. ${ }^{11)}$ The male preponderance in this study was also identical to previous reports by Kaushik et al.,9) Whittaker et al., ${ }^{10)}$ and Gupta et al. ${ }^{12)}$ Table 6 shows the comparison between common clinical features of children in this study and 2 previous studies. ${ }^{10,11)}$ Concordant to previous reports, a greater number of children in our series had multiorgan involvement with gastrointestinal and cardiovascular systems being the most commonly affected systems. ${ }^{11,13-15)}$

The incidence of hematological abnormalities like lymphopenia $(47.6 \%)$ and thrombocytopenia $(38.1 \%)$ in our study was in agreement with previous reports. ${ }^{11,14,16)}$ The majority of children in this study had raised inflammatory markers, which was similar to previous reports by Kaushik et al.,9) Dhanalakshmi et al., ${ }^{11)}$ Feldstein et al., ${ }^{13)}$ and Mamishi et al. ${ }^{16)}$ In contrast to previous studies by Dhanalakshmi et al., ${ }^{11)}$ Feldstein et al., ${ }^{13)}$ Toubiana et al., ${ }^{15)}$ and Miller et al., ${ }^{17)}$ none of the children in this series had acute kidney injury. The incidence of hyponatremia $(70.6 \%)$ in this study was higher than in previous reports by
Dhanalakshmi et al. ${ }^{11)}$ and Mamishi et al. ${ }^{16)}$ Hypokalemia was found in $47.1 \%$ of children, and it was more common in children with gastrointestinal manifestations, which was not reported in any previous studies. Hypoalbuminemia was noted in 52.9\% of children in this study, which was almost similar to previous reports by Dhanalakshmi et al. ${ }^{11)}$ and Mamishi et al. ${ }^{16)}$ The elevation of cardiac biomarkers was also concordant to previous reports by Whittaker et al. ${ }^{10)}$ and Mamishi et al. ${ }^{16)}$ The incidence of echocardiographic abnormalities in this study was comparable to previous reports by Toubiana et al. ${ }^{15)}$ and Ramcharan et al. ${ }^{18)}$ The abnormalities seen in gastrointestinal imaging studies in this study were comparable to the previous report by Miller et al. ${ }^{17)}$

Since MIS-C is an emerging disease, guidelines regarding the management are still evolving and there is a lack of consistency in management. The majority of patients in our study were treated with either IVIG, steroids, or a combination of both and, none required other immunomodulators. The treatment decision for the patients in our study was made based on severity of the illness and the treating physician's discretion. Significant differences in treatment strategies were noted among studies from different parts of the world, which could be due to lack of standard treatment protocols in the initial phase of disease evolution. ${ }^{9-11,14,16)}$ However, a considerable number of studies would be required for developing standard treatment protocols. Concordant to previous reports by Torres et al. ${ }^{14)}$ and Dhanalakshmi et al., ${ }^{11)} 52.4 \%$ of children in this series required PICU admission. The median length of hospital stay was 6 days which was comparable to previous reports. ${ }^{9,14,15)}$ Although previous studies showed variable rates of mortality, no death was reported in this study. ${ }^{11,14,15,17)}$ The follow-up rate in this study was $76.2 \%$. All children had no health concerns at the time of follow-up, and most echocardiographic abnormalities had resolved. However, these children should be followed up at regular intervals to know the long-term consequences of the disease.

A major limitation of this study is that it was conducted in a single center over a limited period of time, and has a small sample size. Another limitation is that this study only included children under the age of 16 years, because our institutional policy defined children under 16 years to be admitted to the pediatric department. It might have missed MIS-C patients older than 16 
years of age.

In conclusion, MIS-C is a novel disease that can present in a myriad of ways with variable severity, and a high index of suspicion is necessary in this era of COVID-19 pandemic for early identification, appropriate management, and favorable outcomes of patients. Further research is essential to develop optimal treatment strategies.

\section{Footnotes}

Conflicts of interest: No potential conflict of interest relevant to this article was reported.

Acknowledgments: Dr. Karthikeyan Shanmugam (Associate professor, Department of Community medicine) for his help in statistical analysis.

\section{ORCID:}

Muruganantham Balagurunathan (D) https://orcid.org/00000002-1428-2147

Thrilok Natarajan (1) https://orcid.org/0000-0003-1589-9162

Jothilakshmi Karthikeyan (D https://orcid.org/0000-0003-29849932

Venkateshwaran Palanisamy (1D https://orcid.org/0000-0002-77799661

\section{References}

1. WHO Coronavirus Disease (COVID-19) Dashboard [Internet]. Geneva (Switzerland): World Health Organization; 2021 [cited 2021 Feb 24]. Available from: https://covid19.who.int/.

2. Castagnoli R, Votto M, Licari A, Brambilla I, Bruno R, Perlini S, et al. Severe acute respiratory syndrome coronavirus 2 (SARS-CoV-2) infection in children and adolescents: a systematic review. JAMA Pediatr 2020;174:882-9.

3. Rodriguez-Morales AJ, Cardona-Ospina JA, Gutiérrez-Ocampo E, Villamizar-Peña R, Holguin-Rivera Y, Escalera-Antezana JP, et al. Clinical, laboratory and imaging features of COVID-19: A systematic review and meta-analysis. Travel Med Infect Dis 2020;34:101623.

4. Ludvigsson JF. Systematic review of COVID-19 in children shows milder cases and a better prognosis than adults. Acta Paediatr 2020;109:108895.

5. Riphagen S, Gomez X, Gonzalez-Martinez C, Wilkinson N, Theocharis P. Hyperinflammatory shock in children during COVID-19 pandemic. Lancet 2020;395:1607-8.

6. Paediatric multisystem inflammatory syndrome temporally associated with COVID-19 (PIMS) - guidance for clinicians [Internet]. London: Royal College of Paediatrics and Child Health; 2021 [cited 2021 Feb 24]. Available from: https://www.rcpch.ac.uk/resources/paediatricmultisystem-inflammatory-syndrome-temporally-associated-covid19-pims-guidance.
7. Emergency preparedness and response. Multisystem inflammatory syndrome in children associated with coronavirus disease 2019 [Internet]. Atlanta (GA): Centers for Disease Control and Prevention; 2020 [cited 2021 Feb 24]. Available from: https://emergency.cdc.gov/han/2020/ han00432.asp.

8. Multisystem inflammatory syndrome in children and adolescents with COVID-19 [Internet]. Geneva (Switzerland): World Health Organization [cited $2021 \mathrm{Feb}$ 24]. Available from: https://www.who.int/news-room/ commentaries/detail/multisystem-inflammatory-syndrome-in-childrenand-adolescents-with-covid-19.

9. Kaushik S, Aydin SI, Derespina KR, Bansal PB, Kowalsky S, Trachtman $\mathrm{R}$, et al. Multisystem inflammatory syndrome in children associated with severe acute respiratory syndrome coronavirus 2 infection (MIS-C): a multi-institutional study from New York City. J Pediatr 2020;224:24-9.

10. Whittaker E, Bamford A, Kenny J, Kaforou M, Jones CE, Shah P, et al. Clinical characteristics of 58 children with a pediatric inflammatory multisystem syndrome temporally associated with SARS-CoV-2. JAMA 2020;324:259-69.

11. Dhanalakshmi K, Venkataraman A, Balasubramanian S, Madhusudan M, Amperayani S, Putilibai S, et al. Epidemiological and clinical profile of pediatric inflammatory multisystem syndrome - temporally associated with SARS-CoV-2 (PIMS-TS) in Indian children. Indian Pediatr 2020;57: 1010-4.

12. Gupta Dch S, Chopra Md N, Singh Md A, Gera R, Chellani Md H, Pandey PhD R, et al. Unusual clinical manifestations and outcome of multisystem inflammatory syndrome in children (MIS-C) in a tertiary care hospital of North India. J Trop Pediatr 2021;67:fmaa127.

13. Feldstein LR, Rose EB, Horwitz SM, Collins JP, Newhams MM, Son MBF, et al. Multisystem inflammatory syndrome in U.S. children and adolescents. N Engl J Med 2020;383:334-6.

14. Torres JP, Izquierdo G, Acuña M, Pavez D, Reyes F, Fritis A, et al. Multisystem inflammatory syndrome in children (MIS-C): report of the clinical and epidemiological characteristics of cases in Santiago de Chile during the SARS-CoV-2 pandemic. Int J Infect Dis 2020;100:75-81.

15. Toubiana J, Poirault C, Corsia A, Bajolle F, Fourgeaud J, Angoulvant F, et al. Kawasaki-like multisystem inflammatory syndrome in children during the covid-19 pandemic in Paris, France: prospective observational study. BMJ 2020;369:m2094.

16. Mamishi S, Movahedi Z, Mohammadi M, Ziaee V, Khodabandeh M, Abdolsalehi MR, et al. Multisystem inflammatory syndrome associated with SARS-CoV-2 infection in 45 children: a first report from Iran. Epidemiol Infect 2020;148:e196.

17. Miller J, Cantor A, Zachariah P, Ahn D, Martinez M, Margolis KG. Gastrointestinal symptoms as a major presentation component of a novel multisystem inflammatory syndrome in children that is related to coronavirus disease 2019: a single center experience of 44 cases. Gastroenterology 2020;159:1571-4.e2.

18. Ramcharan T, Nolan O, Lai CY, Prabhu N, Krishnamurthy R, Richter AG, et al. Paediatric inflammatory multisystem syndrome: temporally associated with SARS-CoV-2 (PIMS-TS): cardiac features, management and short-term outcomes at a UK tertiary paediatric hospital. Pediatr Cardiol 2020;41:1391-401.

How to cite this article: Balagurunathan M, Natarajan T, Karthikeyan J, Palanisamy V. Clinical spectrum and shortterm outcomes of multisystem inflammatory syndrome in children in a south Indian hospital 20212;63:531-7. https://doi. org/10.3345/cep.2021.00374 